\section{cambridge.org/cty}

\section{Images in Congenital Cardiac Disease}

Cite this article: van der Linde D, Budde RPJ, and Roos-Hesselink JW (2021). Coronary aneurysm in a young patient with Turner syndrome. Cardiology in the Young, page 1 of 2 . doi: 10.1017/S1047951121001244

Received: 27 January 2021

Revised: 25 February 2021

Accepted: 9 March 2021

\section{Keywords:}

Turner syndrome; CT; coronary aneurysm

\section{Author for correspondence:}

D. van der Linde, Department of Cardiology, Erasmus Medical Center, PO Box 2040, 3000 CA Rotterdam, the Netherlands. Tel: +31(0)107032432; Fax: +31(0)107035498. E-mail: d.vanderlinde@erasmusmc.nl

\title{
Coronary aneurysm in a young patient with Turner syndrome
}

Denise van der Linde ${ }^{1}$, Ricardo P. J. Budde ${ }^{2}$ and Jolien W. Roos-Hesselink ${ }^{1}$

${ }^{1}$ Department of Cardiology, Erasmus Medical Center, Rotterdam, the Netherlands and ${ }^{2}$ Department of Radiology, Erasmus Medical Center, Rotterdam, the Netherlands

\section{Abstract}

A young woman with Turner syndrome was found to have a large coronary aneurysm in the left anterior descending coronary artery upon CT angiogram screening for aortic pathology.

A 35-year-old woman, known with Turner syndrome, was referred for cardiac screening to our outpatient clinic for adult CHD. As a teenager, cardiac screening had not shown any abnormalities. She has never had any cardiac symptoms and her exercise tolerance is good. Her electrocardiogram and physical examination were unremarkable.

Echocardiography showed a normal bi-ventricular function, no significant valve disease, and mild aortic root dilatation of $37 \mathrm{~mm}$ (corrected for body surface area $22 \mathrm{~mm} / \mathrm{m}^{2}$ ). A CT angiogram confirmed this aortic root dilatation. In addition, the CT angiogram showed an aneurysm of the left anterior descending coronary artery, measuring up to $7.7 \mathrm{~mm}$ (Fig la-c indicated by the arrow). Coronary origins were normal and the other coronaries did not show any abnormalities.

Turner syndrome, also known as $45, \mathrm{X} 0$, is a genetic condition characterised by a range of congenital abnormalities such as webbed neck, short stature, cardiac abnormalities, autoimmune disorders, and reproductive problems. Associated congenital cardiac defects include a bicuspid aortic valve, aortic dilatation, and coarctation of the aorta. Aberrant origin of the coronaries has also been described. ${ }^{1,2}$ However, coronary aneurysms thus far have not been reported. Coronary artery aneurysms are defined as dilatation of the coronary artery exceeding $50 \%$ of the reference vessel diameter. ${ }^{3}$ Our patient did not have any signs of another aetiology for her coronary aneurysm such as the history of Kawasaki syndrome or other associated autoimmune diseases. Therefore, we think that this aneurysm is most likely related to the cardiac phenotype of Turner syndrome, warranting further research in other Turner women. Furthermore, our findings emphasise the key role of multimodality cardiovascular imaging in these patients. ${ }^{4}$

(a)

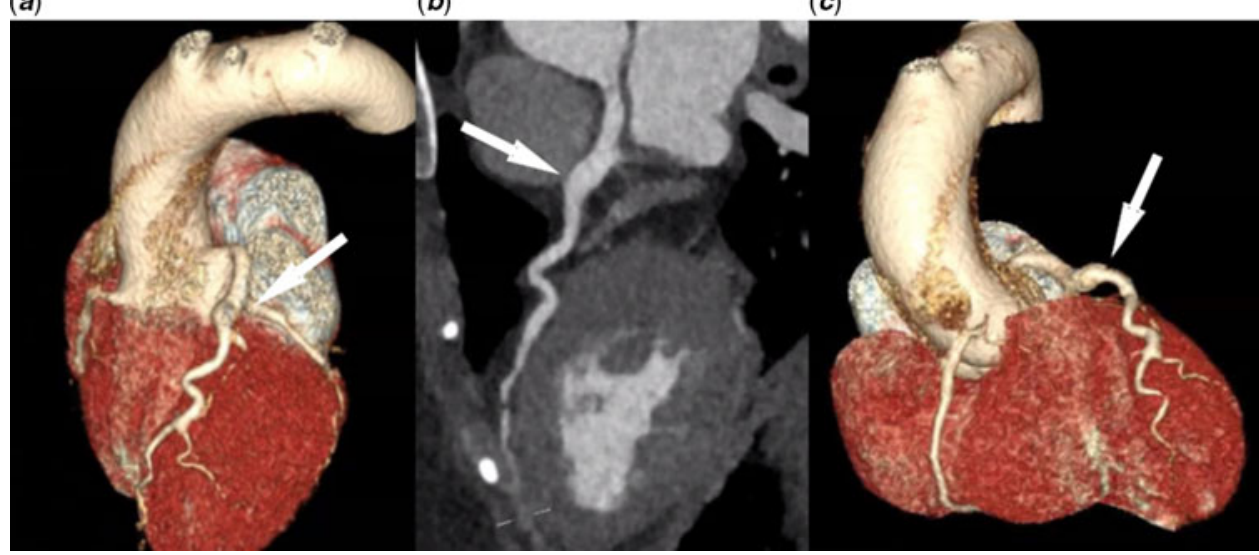

(c) The Author(s), 2021. Published by Cambridge University Press. This is an Open Access article, distributed under the terms of the Creative Commons Attribution-NonCommercialShareAlike licence (http://creativecommons. org/licenses/by-nc-sa/4.0/), which permits noncommercial re-use, distribution, and reproduction in any medium, provided the same Creative Commons licence is included and the original work is properly cited. The written permission of Cambridge University Press must be obtained for commercial re-use.

\section{CAMBRIDGE UNIVERSITY PRESS}

Figure 1. Arrow indicates a large coronary aneurysm in the left anterior descending coronary artery, measuring up to $7.7 \mathrm{~mm}$.

Acknowledgements. We all contributed to the clinical management of the patient. DvdL wrote the manuscript and RB prepared the images. All authors reviewed the manuscript. Written consent for publication was obtained from the patient. The authors do hereby declare that all illustrations and figures in the manuscript are entirely original and do not require reprint permission.

Financial support. This research received no specific grant from any funding agency, commercial, or not-forprofit sectors.

Conflicts of interest. None. 
Ethical standards. The authors declare that they comply with appropriate institutional and international guidelines for ethical guidelines. Informed consent was obtained from the patient to publish this case report.

\section{References}

1. Viuff MH, Trolle C, Wen J, et al. Coronary artery anomalies in Turner Syndrome. J Cardiovasc Comput Tomogr 2016; 10: 480-484. doi: 10.1016/j.jcct.2016.08.004
2. Funck KL, Budde RPJ, Viuff MH, et al. Coronary plaque burden in Turner syndrome a coronary computed tomography angiography study. Heart Vessels 2020. doi: 10.1007/s00380-020-01660-7.

3. Swaye PS, Fisher LD, Litwin P, et al. Aneurysmal coronary artery disease. Circulation 1983; 67: 134-138.

4. Mortensen KH, Young L, De Backer J, et al. Cardiovascular imaging in Turner syndrome: state-of-the-art practice across the lifespan. Heart 2018; 104: 1823-1831. doi: 10.1136/heartjnl-2017-312658. 